\title{
Correlation of NT-PROBNP levels with Physical and Biochemical Parameters in Egyptian Patients with Type 2 Diabetes
}

\author{
Mona Sadek ${ }^{1}$ Hassan Shora ${ }^{2 *}$, Lamia Barakat ${ }^{3}$ and Naglaa El-Liethy ${ }^{4}$ \\ 'Professor of Biochemistry, Faculty of Girls, Ain Shams University, Cairo Egypt. \\ ${ }^{2}$ Department of Biochemistry, Port-said University, Egypt. \\ ${ }^{3}$ Professor\&Head of Department of Biochemistry, Port-Said University, Egypt.
}

${ }^{4} \mathrm{MSc}$ student, Faculty of Science, Port-Said University, Egypt.

*Address for Correspondence: Hassan Shora, Senior Researcher, Port-Said University \& Head of Medicine and Diabetes Center, Ismailia General Hospital, Ismailia 064,Egypt. E mail: Hassanshora56@gmail.com

Received: 16 July 2020; Accepted: 01 August 2020; Published: 03 August 2020

Citation of this article: Sadek M, Shora H, Barakat L, El-Liethy N (2020) Correlation of NT-PROBNP levels with Physical and Biochemical Parameters in Egyptian with Type 2 Diabetes.. Rea Int J of End and Diabe. 1(1): 013-017.

DOI: $10.37179 /$ rijed.000004.

Copyright: (C) 2020 Sadek M, et al. This is an open access article distributed under the Creative Commons Attribution License, which permits unrestricted use, distribution, and reproduction in any medium, provided the original work is properly cited.

\footnotetext{
ABSTRACT

Background: The N-terminal pro brain natriuretic peptide (Nt-proBNP) is a marker of cardiac dysfunction. This study aimed to detect the association of natural pro brain natruritic peptide with renal impairment parameters in Egyptian type 2 in diabetic patients with microangiopathy.

Methods: we evaluated the Nt-proBNP levels 94 type 2 diabetic patients with and without microangiopathy and correlate them with various patients physical and biochemical parameters.

Results: Nt-proBNP levels were significantly correlated with renal impairment parameters.

Conclusions: Nt-proBNP levels assessment in diabetic patients with microangiopathy may have an important role in detecting early stage of diabetic nephropathy so that enable prevention of its development and progression.

Keywords: Type 2 Diabetes Mellitus, Nt-proBNP, and Nephropathy.
}

\section{Introduction}

Diabetes mellitus (DM) is a group of metabolic diseases characterized by hyperglycemia resulting from defect in insulin secretion, insulin action or both. It is an important cause of morbidity and mortality worldwide [1]

Complications of diabetes contribute greatly to the increased mortality and morbidity associated with this disease. Diabetic complications are divided into two main categories: macrovascular complications, including heart disease and stroke, and microvascular complications, which include retinopathy, nephropathy, and neuropathy. In the multinational A1chieve study, a large global study, based on nearly 68,000 type 2 diabetics, microvascular complications accounted for about half the total number of complications [2].

Diagnostic and prognostic values of B-type natriuretic peptides (BNP) and N-terminal fragment brain natriuretic peptides (NTpro-BNP) BNP was initially discovered in the porcine brain, but the largest concentrations are found in the heart [3]. BNP is mainly synthesized and secreted by cardiomyocytes of left ventricle (LV) in response to stretched cardiomyocytes by pressure overload or volume expansion of the ventricle. 
Other direct and indirect stimuli may include ischemia/ reperfusion injury, inflammation, hormones such as catecholamines, aldosterone and growth factors of transforming growth factor superfamily. Recently, subclinical abnormalities in cardiac structure have been associated with longitudinal kidney function decline indicating a close relationship of two organs, i.e., cardio-renal continuum [4]. The aim of this study is to detect the association of natural pro brain natruritic peptide with renal impairment parameters in type 2 in diabetic patients with microangiopathy.

\section{Materials and Methods}

This study took place at diabetes outpatient clinic of Ismailia General Hospital. Patients attended the outpatient clinic for treatment or follow up of type 2 diabetes were eligible for the study. Cases subjects of the study were selected randomly, based on inclusion criteria that included age range 50-60 years with history of type 2 diabetes on oral hypoglycemic drugs of more than ten years duration.

The biochemical study was done in the laboratory department. The study was approved by institutional ethical committee board.

\section{Patient selection}

This study was conducted on ninety four (94), type 2 diabetic patients, aged more than 60 years both males and females with duration of diabetes over 10 years, 28 males and 66 females, patients known to have heart or renal failure (on dialysis) were excluded from the study.

All patients were subjected to clinical history taking, clinical examination: Measurement of BMI (weight in $\mathrm{Kg} /$ height in meter ${ }^{2}$ ) [5], blood pressure measurement.

\section{Laboratory investigations}

Urine albumin was measured by latex turbidimetry method [6] and urine creatinine was measured by Jaffe's kinetic method [7] Albumin / Creatinine ratio (ACR) was calculated by dividing albumin concentration in milligrams by creatinine concentration in mmol [8]. Blood samples were drawn and following tests were done: Fasting blood glucose (FBG) level by colorimetric method [9], Hb A1C [10], albumin [11], creatinine [12] and high sensitivity C-rective protein (hs-CRP) levels [13]. Serum Human N-terminal pro-brain natriuretic peptide (NT-proBNP) was analyzed by ELISA Kit from the manufacturing company (Sun Red, Gentaur, Belgium).

\section{Statistical analysis}

Data was tabulated and introduced into a PC using SPSS 15.0.1. Mean, standard deviation, median, minimum and maximum values for numerical data and frequency and percentage for non-numerical data were calculated.

Student t-test was used to assess the statistical significance of the difference between 2 means of 2 independent groups. Chi-square test was used for the relation between two qualitative variables. Pearson's Product correlation coefficient was used to evaluate the linear association between 2 quantitative variables. P-value: $p>0.05$ : Not significant, $p<0.05$ : Significant, $p<0.01$ : Highly significant.

\section{Results}

The mean FBG was $182.22 \pm 69.43 \mathrm{mg} / \mathrm{dL}, \mathrm{HbAlc}$ was $7.76 \pm$ $1.16 \%$, serum creatinine was $1.4 \pm 0.87 \mathrm{mg} / \mathrm{dL}$, ACR was $41.76 \pm$
$17.32 \mathrm{mg} / \mathrm{mmol}$, urine albumin was $20.57 \pm 22.94 \mathrm{mg} / \mathrm{hr}$, hs-CRP was $2.52 \pm 0.99 \mathrm{mg} / \mathrm{L}$ and finally the mean of NT-proBNP level was 67.56 $\pm 12.14 \mathrm{pg} / \mathrm{mL}$, of On comparing both sexes, there was no statistical significant difference of serum Human $\mathrm{N}$-terminal pro-brain natriuretic peptide (NT-proBNP) levels. Correlation of NT-proBNP level with various parameters are shown in (Table 1):

Table 1: Correlations between Serum Human N-terminal pro-brain natriuretic peptide (NT-proBNP) and other parameters in the study subjects.

\begin{tabular}{|c|c|c|}
\hline \multirow{2}{*}{ Variables } & \multicolumn{2}{c|}{ NT-proBNP } \\
\hline Age (years) & 0.297238 & P \\
\hline BMI(kg/m2) & 0.171792 & $<0.01$ \\
\hline FBG (mg/dL) & 0.631393 & $<0.05$ \\
\hline Hb A1c (\%) & 0.727989 & $<0.01$ \\
\hline ACR (mg/mmol) & 0.663331 & $<0.01$ \\
\hline Creatinine (mg/dL) & 0.51904 & $<0.01$ \\
\hline Albumin/urine (mg/hr) & 0.304031 & $<0.01$ \\
\hline CRP & 0.6678 & $<0.01$ \\
\hline
\end{tabular}

The study subjects were further sub-classified according to the presence of evidence of nephropathy as diagnosed by the renal function tests into diabetic and diabetic with microangiopathy (Table 2).

The cut off value of the NT-proBNP levels for differentiation between the diabetic patients and the diabetic patients with microangiopathy was $75 \mathrm{pg} / \mathrm{mL}$ (Figure 1).

\begin{tabular}{|c|c|c|}
\hline Table 2: & \multicolumn{2}{|c|}{} \\
\hline Subgroup & N & Percentage \\
\hline Diabetic & 19 & $79.79 \%$ \\
\hline Diabetic with microangiopathy & 75 & $20.21 \%$ \\
\hline
\end{tabular}

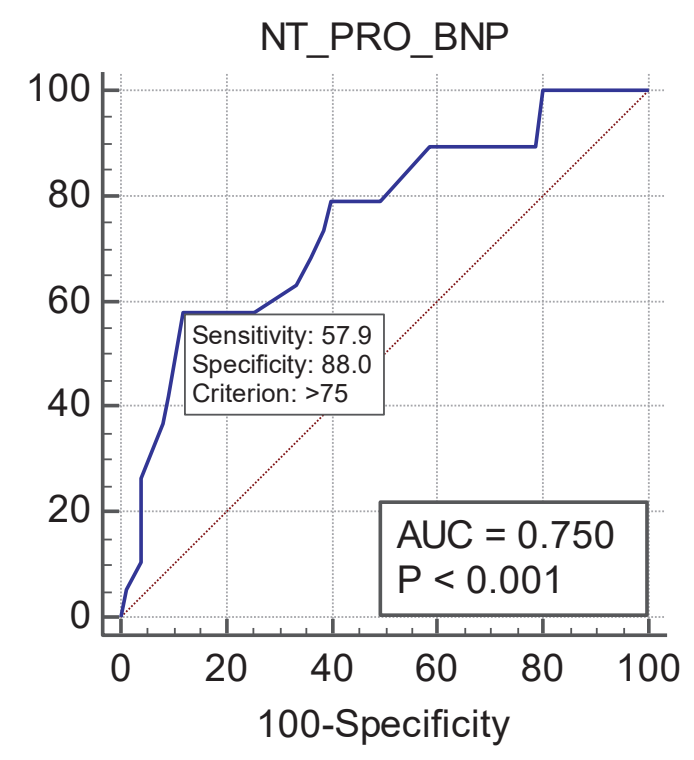

Figure 1: ROC curves evaluation of Serum Human NT-proBNP levels in diabetic and diabetic with micrangiopathy patients. 


\section{Discussion}

Diabetes is associated with an increased risk of microvascular and macrovascular disease. B-type natriuretic peptide (BNP) and the $\mathrm{N}$-terminal part of the precursor molecule proBNP (NT-proBNP), in particular, are established biomarkers of cardiovascular (CV) stress in diabetic patients [14].

Increased secretion of BNP and Nt-proBNP occurs mainly with increased tension in the ventricular walls, decreased oxygen supply, acute myocardial infarction, chronic cardiac heart failure, and in hypertrophy of the heart [15]. This study was conducted to reveal the association of natural pro brain natruritic peptide with renal impairment parameters in type 2 in diabetic patients with microangiopathy.

This study showed no significant difference between both sexes in serum Human N-terminal pro-brain natriuretic peptide (NTproBNP) levels, that was in agreement with other studies [16] and discordant with previous studies [17, 18]. However, those study subjects suffered from chronic cardiac complications. In this study, levels of NT-proBNP were correlated with the various studied parameters, NT-proBNP level increased with age, in concordance with Vasilkova et al (2017) study which confirmed this positive correlation [19]. Furthermore, NT-proBNP levels was positively correlated with BMI.

The true implications of NT-proBNP in clinical practice were typically influenced by confounders, such as age, sex, diabetes, and renal function. Recently, a study showed that BMI was inversely associated with BNP/NT-proBNP levels [20]. Some of the possible explanations for this phenomenon include an increase in the clearance of natriuretic peptide by the C-type natriuretic peptide receptor, impairment of the natriuretic peptide response termed "natriuretic peptide handicap", and compromised detection of NTproBNP in obese individuals.

However, some of these hypotheses have been contradicted [21]. Therefore, the exact mechanism underlying the association between NPs and obesity remains elusive. A previous study proposed a bidirectional relationship between BNP and adiposity because BNP has been shown to cause lipolysis via A-type natriuretic peptide receptor [22]. Additionally, Li et al. (2014) recently suggested that increased body fat were associated with increases in plasma NP levels in obese type 2 diabetic patients [23]. Our finding that NT-proBNP levels increase with the higher BMI supports this hypothesis.

In this study, NT-proBNP was significantly correlated with FBG and $\mathrm{HbAlc}$ showing the association between poor glycemic control and myocardial stress. This is in agreement with previous studies [19, 24].

The reason of association between hyperglycemia and increased BNP levels is not obvious. Hyperglycemia may induce dysfunction of cardiomyocytes. Endoplasmic reticulum stress associated with diabetes leads to cardiomyocytes apoptosis and cardiomyopathy as well. Diabetic cardiomyopathy is not uncommon leading to sudden cardiac death and an early diagnosis by measuring NT Pro BNP can initiate timely intervention [25].

In this study, significant positive correlation were found between CRP and NTproBNP levels, this is in agreement with the previous studies [26], the potential role of CRP as a marker of chronic inflammation was explored [27].
NT-proBNP was positively associated with inflammatory biomarkers. Our results confirm the conclusion of a previous study by Jensen et al. that suggested a positive relationship between NTproBNP and inflammatory markers including CRP in European (Swedish) men and woman [28]. Therefore, our results suggest that a potential low-grade inflammatory state that may predispose them to development of subclinical cardiac strain and future cardiovascular ev ents.

C-reactive protein (CRP) is synthesized by the liver and has been shown to be a sensitive and systemic biomarker of inflammation. However, the lack of concordance between the effect of CRP genotypes and CRP levels on T2D risks argues against a causal role of CRP in the etiology of this disease. Otherwise, it could be a marker of hyperglycaemia in the pathway of T2DM and the associated systemic inflammatory process [29-32].

Our results demonstrated that serum NT-proBNP levels significantly positively correlated with ACR, serum creatinineand urine albumin. NT-proBNP has consistently been found to be associated with impaired renal function indicators as shown in previous studies [33].

Only a limited portion of the literature is available on the predictive properties of NTproBNP in renal disease progression, and, to the best of our knowledge, very few of these studies were performed exclusively in patients with diabetes who had impaired renal function [34]. Previously, in a large cohort of elderly (mainly nondiabetic) patients in the Cardiovascular Health Study [35], NTproBNP was associated with rapid renal function decline and onset of CKD. Furthermore, BNP and NTproBNP were found to predict the progression of nondiabetic CKD in patients with mild to moderate nondiabetic kidney disease [36].

In this study the prevalence of nephropathy among the diabetic patients were found to be $20.21 \%$. This result is partially comparable with the linear relationship between microvascular complications and duration of disease was established by the authors where they documented the presence of microvasculopathy across different age groups in their study in $25-40 \%$ of diabetic patients aged $>25$ years with more than 5 years duration of diabetes.

Although intensive glycemic control lowers the incidence and progression of microvascular complications, the morbidity associated with these complications is still increasing $[37,38]$.

Some of renal function parameters were evaluated in this study as serum createnine, albumin, urine albumin, creatinine and urine albumin creatinine ratio (ACR). Although the 24-hour urine collection was previously the gold standard for the detection of microalbuminuria, it has been suggested that screening can be more simply achieved by a timed urine collection or an early morning specimen to minimize changes in urine volume that occur during the day.

Use of the albumin/creatinine ratio in a timed urinary sample is now recommended as the preferred screening strategy for all diabetic patients [33].In a recent large (CRC) study that involved more than 3,000 adults with Chronic Kidney Disease CKD, it was found that NTproBNP strongly associated with CKD progression. This suggested the possible link between cardiac stress and renal mechanisms that contribute to kidney disease progression $[39,40]$. 
Finally, in this study, the usefulness of NT-proBNP levels as discriminator for the development of nephropathic complications was tested using Roc curves analysis, it was found that the cut off value for differentiation between diabetic those who developed nephropathic complications was $75 \mathrm{pg} / \mathrm{mL}$, with high sensitivity and specificity. To the best of our knowledge, the present study is the first attempting to provide cut off value for the discrimination of diabetic cases and those with nephropathic complications.

\section{Conclusion}

Measuring Nt-proBNP levels in diabetic patients with microangiopathy may have an important role in early detection of Diabetic kidney Disease for possible future prevention of the development and halt the progression of diabetic nephropathy.

\section{References}

1. World Health Organization (2016) Global report on diabetes. Geneva. Link: https://bit.ly/30iuu6X

2. Cheema S, Maisonneuve P, Zirie M, Jayyousi A, Alrouh H, et al. (2018) Risk Factors for Microvascular Complications of Diabetes in a High-Risk Middle East Population. Journal of Diabetes Research 2: 8964027. Link: https://bit. ly/3gjkEHp

3. Maries L, Manitiu I (2013) Diagnostic and prognostic values of B-type natriuretic peptides (BNP) and N-terminal fragment brain natriuretic peptides (NT-proBNP). Cardiovasc J Afr 24: 286-289. Link: https://bit.ly/2BOXwl9

4. Dzau VJ, Antman EM, Black HR, David LH, JoAnn EM, et al. (2006) The cardiovascular disease continuum validated: clinical evidence of improved patient outcomes: part II: clinical trial evidence (acute coronary syndromes through renal disease) and future directions. Circulation 114: 2871-2891. Link: https://bit.ly/3fjFyoD

5. Panagiotakos D, Tzima N, Pitsavos C, Chrysohoou C, Papakonstantinou E, et al (2005) The Relationship between Dietary Habits, Blood Glucose and Insulin Levels among People without Cardiovascular Disease and Type 2 Diabetes; The ATTICA Study. Rev Diabet Stud 2: 208-215. Link: https://bit.ly/3hZgODw

6. Bernard A, Vyskocil A, Lauwerys R (1981) Latex immunoassay of retinolbinding protein Clin. Chem 27: 832-837. Link: https://bit.ly/2D8pEjJ

7. Peake M, Whiting M (2006) Measurement of serum creatinine-current status and future goals. Clin Biochem Rev 27: 173-184. Link: https://bit.ly/2PrJpFH

8. Lambers Heerspink HJ, Brantsma AH, de Zeeuw D, Bakker SJ, de Jong PE, et al. (2008) Albuminuria assessed from first-morning-void urine samples versus 24 hour urine collections as a predictor of cardiovascular morbidity and mortality. Am J Epidemiol 168: 897-905. Link: https://bit.ly/2Do5VfQ

9. Pal S, Lim S, Egger G (2008) The Effect of a Low Glycaemic Index Breakfast on Blood lucose, Insulin, Lipid Profiles, Blood Pressure, Body Weight, Body Composition and Satiety in Obese and Overweight Individuals: A Pilot Study. Journal of the American College of Nutrition 27: 387-393. Link: https://bit. ly/30i7p 4 e

10. Hempe JM, Soros AA, Chalew SA (2010) Estimated average glucose and selfmonitored mean blood glucose are discordant estimates of glycemic control. Diabetes Care 33: 1449-1451. Link: https://bit.ly/2Dndxz4

11. Stanley FLo, Greg WM, Basil TD (2013) Laboratory Performance in Albumin and Total Protein Measurement Using a Commutable Specimen: Results of a College of American Pathologists Study. Archives of Pathology \& Laboratory Medicine 137: 912-920. Link: https://bit.ly/3gmn1t2

12. Drion I, Cobbaert C, Groenier KH, Weykamp C, Bilo HJ, et al. (2012) Clinical evaluation of analytical variations in serum creatinine measurements: why laboratories should abandon Jaffe techniques. BMC nephrology 13:133. Link: https://bit.ly/3jYDtlz
13. Ridker P, Rifai N, Rose L, Julie EB, Nancy RC (2002) Comparison of C-reactive protein and low-density lipoprotein cholesterol levels in the prediction of first cardiovascular events. New England Journal of Medicine 347: 1757-1565. Link: https://bit.ly/3hZT1D0

14. Hijazi Z, Oldgren J, Anderson U, Stuart JC, Michael DE, et al. (2012) Cardiac biomarkers are associated with an increased risk of stroke and death in patients with atrial fibrillation: a Randomized Evaluation of Long-term Anticoagulation Therapy (RE-LY) sub study. Circulation 125: 1605-1616. Link: https://bit. ly/2BQMRWZ

15. Magnusson M, Melander O, Israelsson B, Grubb A, Groop L, et al. (2004) Elevated Plasma Levels of Nt-proBNP in Patients With Type 2 Diabetes Without Overt Cardiovascular Disease. Diabetes Care 27: 1929-1935. Link: https://bit. ly/2XA8McT

16. Seki N, Nishimura M, Matsumoto T, Fukazawa M, Kenmochi T (2013) Relationship between BNP level and renal function in diabetic nephropathy with microalbuminuria. Journal of Diabetes and Its Complications 27: 92-97. Link: https://bit.ly/30iAwnS

17. Leosdottir M, Willenheimer R, Hall C, Tjora S, Malm J, et al. (2011) Age and Gender Differences in the Association Between Nt-proBNP and Glucometabolic Disturbances. Scand Cardiovasc J 45: 294-300. Link: https://bit.ly/3k4ynnC

18. Aimo A, Januzzi J, Vergaro G, Ripoli A, Latini R, et al. (2019) Sex differences in plasma concentrations and prognostic value of NT-proBNP in chronic heart failure. Journal of the American College of Cardiology 73: 1. Link: https://bit. ly/3fm6Jig

19. Vasilkova V, Mokhort T, Naumenko E, Zmailik M (2017) N-Terminal pro-B-type natriuretic peptide level in type 2 diabetic patients. Endocrine Abstracts 49: 511. Link: https://bit.ly/2EHsvRc

20. Wang TJ, Larson MG, Levy D, Benjamin EJ, Leip EP, et al. (2004) Impact of obesity on plasma natriuretic peptide levels. Circulation 109: 594-600. Link: https:// bit.ly/33i4bzC

21. Das SR, Drazner MH, Dries DL, Vega GL, Stanek HG, et al. (2005) Impact of body mass and body composition on circulating levels of natriuretic peptides: results from the Dallas Heart Study. Circulation 112: 2163-2168. Link: https://bit ly/2EzCNTc

22. Madamanchi C, Alhosaini H, Sumida A, Runge MS (2014) Obesity and natriuretic peptides, BNP and NT-proBNP: mechanisms and diagnostic implications for heart failure. Int J Cardiol 176: 611-617. Link: https://bit.ly/2Dw95xR

23. Li CJ, Yu Q, Yu P, Yu TL, Zhang QM, et al. (2014) Changes in liraglutide-induced body composition are related to modifications in plasma cardiac natriuretic peptides levels in obese type 2 diabetic patients. Cardiovasc Diabetol 13: 36. Link: https://bit.ly/3hZrsKJ

24. Mishra A, Bhanja S (2018) An Interrelationship between NTproBNP Level, Glycemic Control and Myocardial Ischemia in Type 2 Diabetes without Overt Cardiac Disease. IOSR Journal of Biotechnology and Biochemistry (IOSR-JBB) 4: 12-16. Link: https://bit.ly/319302P

25. Lakshmanan AP, Meilei H, Suzuki K, Vivian S, Masaki N, et al. (2013) The hyperglycemia stimulated myocardial endoplasmic reticulum (ER) stress contributes to diabetic cardiomyopathy in the transgenic non-obese type 2 diabetic rats: A differential role of Unfolded Protein Response (UPR) signaling proteins. Int J Biochem Cell Biol 45: 438-447. Link: https://bit.ly/315akfl

26. Baldassarre S, Fragapani S, Panero A, Fedele D, Pinach S, et al. (2019) NTproBNP in insulin-resistance mediated conditions: overweight/obesity, metabolic syndrome and diabetes. The population-based Casale Monferrato Study. Cardiovascular Diabetology 16: 119. Link: https://bit.ly/2PgoJAb

27. Xu H, Barnes TG, Yang Q, Tan G, Yang D, et al. (2003) Chronic inflammation in fat plays a crucial role in the development of obesity-related insulin resistance. Clin Invest 112: 1821-1830. Link:

28. Jensen J, Ma L, Fu MLX, Svaninger D, Lundberg P, et al (2010) Inflammation increases NT-proBNP and the NT-proBNP/BNP ratio. Clin Res Cardiol 99: 445452. Link: https://bit.ly/33o9MVb 
Citation: Sadek M, Shora H, Barakat L, El-Liethy N (2020) Correlation of NT-PROBNP levels with Physical and Biochemical Parameters in Egyptian Patients with Type 2 Diabetes. Rea Int J of End and Diabe. 1(1): 013-017. DOI: 10.37179/rijed.000004.

29. Mankowska A, Pollak J, Sypniewska G (2006) Association of C - reactive protein and Other Markers of Inflammation with Risk of Complications in Diabetic Subjects. EJIFCC 17: 8-11. Link: https://bit.ly/2DqKDhC

30. Schmidt FM, Weschenfelder J, Sander C, Juliane M, Julia T, et al. (2015) Inflammatory Cytokines in General and Central Obesity and Modulating Effects of Physical Activity. PLoS One 10: e0121971. Link: https://bit.ly/3hZzPpu

31. Barakat L, Shora H, El-Deen I, El-Sayed ES (2017) Inflammatory Biomarkers of Cardio metabolic Risk in Obese Egyptian Type 2 Diabetics. Med Sci 5: 25. Link https://bit.ly/3k2pB9E

32. Pan A, Wang Y, Yuan J, Woon-PK (2017) High-sensitive C-reactive protein and risk of incident type 2 diabetes: a case-control study nested within the Singapore Chinese Health Study. BMC Endocr Disord 17: 8. Link: https://bit ly/2DuN5nm

33. Bruno G, Barutta F, Landi A, Cavallo PP, Gruden G (2014) NT-proBNP Linking Low Moderately Impaired Renal Function and Cardiovascular Mortality in Diabetic Patients: The Population-Based Casale Monferrato Study. PLoS ONE 9: e114855. Link:' https://bit.ly/3gk9B0I

34. Bidadkosh A, Lambooy S, Heerspink H, Pena M, Henning R, et al. (2017) Predictive Properties of Biomarkers GDF-15, NTproBNP, and hs-TnT for Morbidity and Mortality in Patients With Type 2 Diabetes With Nephropathy. Diabetes Care 40: 784-792. Link: https://bit.ly/3gmijLQ
35. Bansal N, Katz R, Dalrymple L, Ian de B, Christopher D, et al (2015) NT-proBNP and troponin $\mathrm{T}$ and risk of rapid kidney function decline and incident CKD in elderly adults. Clin J Am Soc Nephrol 10: 205-214. Link: https://bit.ly/30ipT4A

36. Spanaus KS, Kronenberg F, Ritz E, Ralph S, Danilo F, etal. (2007) Mild-to-Moderate Kidney Disease Study Group. B-type natriuretic peptide concentrations predict the progression of nondiabetic chronic kidney disease: the Mild-to-Moderate Kidney Disease Study. Clin Chem 53: 1264-1272. Link: https://bit.ly/3goRU02

37. Atwa H, Shora H, Fahmy H (2011) Normal adiponectin and glycemic control could delay subclinical atherosclerotic changes in lean type 1 diabetic children. J Med Sci 11: 145-151 Link: https://bit.ly/3gxwhKI

38. Chawla A, Chawla R, Jaggi S (2016) Microvascular and macrovascular complications in diabetes mellitus: Distinct or continuum? Indian J Endocrinol Metab 20: 546-551. Link: https://bit.ly/33ejzgl

39. Momin AR, Pankaja SN, Gouri MB (2011) Albumin/Creatinine Ratio, As Predictor of Microalbuminuria, a Risk Factor for Nephropathy in Type 2 Diabetes Mellitus Patients. International journal of health sciences and research 4: 256. Link: https://bit.ly/2D966vu

40. Bansal N, Zelnick L, Shlipak MG, Anderson A, Christenson R, et al. (2019) Cardiac and Stress Biomarkers and Chronic Kidney Disease Progression: The CRIC Study. Clin Chem 65: 1448-1457. Link: https://bit.ly/31972YR 